\title{
Travel Characteristics of Female Students to Colleges in the Kingdom of Saudi Arabia
}

\author{
H.M. Al-Ahmadi* \\ Civil Engineering Department, College of Engineering, King Fahd University of Petroleum and Minerals, \\ P.O. Box 31261, Dhahran, Saudi Arabia
}

Received 8 July 2003; accepted 26 March 2005

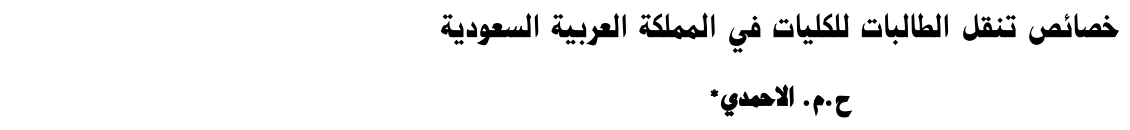

الغلامسة: تركز هذه الدراسة على معرفة خصائص تنقل الطالبات المقيهات بالقرى و الهجر للكليات والجامعات بالمدن الحمول على الثهادة الجامعية. ونظراً لعدم السهاح للمراه

بالقيادة في الهملكة العربية السعودية تعتهد الطالبات على الرجل في التنقل للكليات. ومن نتائج الدراسة ان اغلب الطالبات يواجهن بعض الصعوبات في عملية التنقل. وهذه

النتائج اعتمدت على استبانات أعدت لهذا الغرض ، وزعت على عينات عشوائية من الطالبات المتنقلات للكليات في مختلف مناطق الهملكة. وتحتوي هذه ألورقة على تحليل هفصل

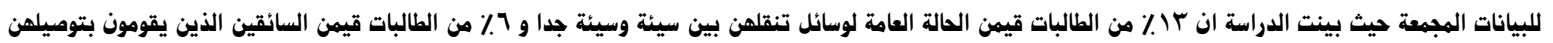

أنهم غير ملتزمين بقواعد القيادة الآمنة وان ب\% من الطالبات لا يتوفر لهن بدائل تنقل أخري غير الوسيلة المستخدمة حاليا.

الهغردات الهنتاهية: المملكة العربية السعودية، القيادة الامنة، خصائص الطالبات المتنقلات للكليات، أعهار السائقين ، وسيلة النقل.

\begin{abstract}
This study is focused on the problems faced by female students residing in the Kingdom of Saudi Arabia. Many of these female students live far from their colleges and they have to travel from villages to cities in order to obtain a university degree. In so doing they travel long distances everyday using various modes of transport. As they are not permitted to drive, these students depend on male drivers to take them to their colleges. The aim of this study was to investigate and identify problems associated with such modes of transport. Results show that most students experience some problems and encounter disproportionate levels of hardship. The findings were based on a survey carried out in the Kingdom and was distributed to representative sample of female students. This paper includes a detailed analysis of the data from which a number of conclusions and recommendations were made. The conclusions suggested that the travel situation encountered by female students who travel by passenger car could be improved in terms of time, cost and convenience. Thirteen percent of female students rated the vehicles they used to be in unacceptable condition for traveling while $6 \%$ marked the drivers as not violating traffic rules, and the majority (53\%) was captives to their current mode of transportation.
\end{abstract}

Keywords: Saudi Arabia, Travel characteristics, College female students, Driver performance, Mode of transportation

\section{Introduction}

The Kingdom faces problems similar to those of arid zones having vast areas. The Kingdom of Saudi Arabia is a large country (over 2.2 million square kilometers), occupying an area approximately the size of Western Europe or one-fourth the size of the United States. It has a population of approximately 20 million scattered throughout the country with major concentrations in several distinct regions (Ministry of Planning, Saudi Arabia, 2001). Generally, the weather in Saudi Arabia is arid and hot, with some of the earth's harshest terrain.

*Corresponding author's e-mail: ahmadi@kfupm.edu.sa
Furthermore, the Kingdom includes features from mountains in the southwest and near the Red Sea, to sand dunes in the central and eastern parts of the country. Female students that attend colleges in the Kingdom are about 95,000 . The media has raised some concern about the difficulties faced by girls traveling to the cities for their studies. In order to reduce travel hazards experienced by female students, some newspapers have suggested that new colleges to be opened near villages. The purpose of this study is to examine difficulties associated with female students traveling from villages into cities. The main goal is to investigate the characteristics of their trips and offer some recommendations in order to improve the conditions in which they travel. 
This paper specifically addresses objectives to define characteristics of female student travel from the village to the City, which include but not limited to the investigation of the proportion of 'captive' female students in Saudi Arabia and investigation of the characteristics of the students' daily trips to and from college.

\section{Sampling}

As a homogeneous group, female students seeking their university degree were chosen as the subjects of this study, because they form a special group who experiences a unique set of problems relating to their travel requirements. They start their journey at dawn, some of them travel hundreds of kilometers before reaching their destination. This is, therefore, an exhausting ordeal. These students have access to a variety of road transportation including passenger cars, SUVs (sports utility vehicle) called 'suburban' in Saudi Arabia, taxis, buses, or minivans.

More than 2000 questionnaires were sent to the Deans of Colleges to distribute to female students coming from villages to study. Three follow-up request letters were sent out before an acceptable number of questionnaires were received. This number was 1360 of the total questionnaires distributed. Of these, 428 were rejected due to the fact that the female students were living in the city. Finally, 892 questionnaires were deemed acceptable for analysis.

\section{Data Collection}

The characteristics were obtained mainly from a data set which was collected as part of this study. The data of this paper were generated from a comprehensive study (Al-Ahmadi, et al. 2002). The first step involved reviewing a number of sources of information appropriate to the subject. These included a literature survey, expert opinion, focus group meetings and common sense. This process was difficult and required several iterations before a satisfactory set of variables was obtained from which a pool of variables was prepared. These included: time, distance and cost of trips; driver nationality, age and performance; mode of transportation chosen and reason for the choice; vehicle owner, manufacturer and condition.

The second step was the development of the survey instrument, which took the form of a self-response type questionnaire. It was first sent to the Department of Girls' Education where it was extensively reviewed and tested to assure that no ambiguities were contained in the list. The questionnaire was then sent through the Ministry of Education to selected colleges. Selection was based on criteria associated with typographical features throughout Saudi Arabia (Ministry of Education, Saudi Arabia). Table 1 shows the list of colleges where the questionnaire was distributed.

Table 1. The Colleges that the questionnaires were distributed

\section{College}

Intermediate College

Intermediate College

Intermediate College

Intermediate College

College of Education Science

Department

College of Education Science

Department

College of Education Science

Department

College of Education Science

Department

College of Education Science

Department

College of Education Science

Department

College of Education Science

Department

College of Education Science

Department

College of Science

College of Education

College of Education Science

Department

College of Science

\begin{tabular}{l}
\multicolumn{1}{c}{ City } \\
Al-Nimas \\
Al-Ula \\
Qwaieh \\
Qariyat \\
Makkah Al- \\
Mokarramah \\
Hail \\
Majmaah \\
Jizan \\
Tabuk \\
Al-Ahsa \\
Al-Kharj \\
Abha \\
Dammam \\
Unayzah \\
Al-Baha \\
Taif
\end{tabular}

\section{Data Analysis}

Primary analysis revealed a number of interesting factors. First, it was found that $14 \%$ of female students traveling from village to city were married. Second, female students spent, on average, 393 Riyals monthly on their travel. Third, vehicle occupancy was on average 20 students per vehicle. Fourth, analysis of driver ownership showed that $65 \%$ of the drivers owned the vehicles. Finally, statistics for the time and distance of travel revealed that, on average, each one-way trip was $55 \mathrm{~km}$ long and took 55 minutes. Detailed analyses of the other characteristics are as follows:

\subsection{Driver Age}

Figure 1 shows that $69 \%$ of the drivers were aged 30 50. Drivers of this age group generally do not suffer from health issues associated with older drivers, such as poor eyesight, which may negatively impact their driving (Forbes, 1972). Also, these drivers were mature and possess experience, expertise and knowledge of the road rules which is importance during th driving. Drivers under the age of $30(15 \%)$, on the other hand, may possess poorlydeveloped attitudes towards driving. Accordingly, there are many concerns with this age group regarding the ignoring of road rules, dangerous driving and incidents involving anger and immaturity (Al-Shara, Alsaef, 1988; Shipp, 1988). 


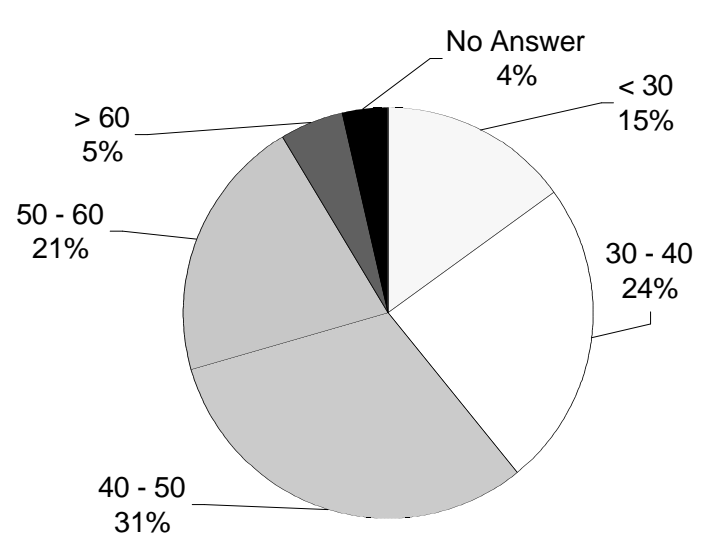

Figure 1. Pie chart for driver age

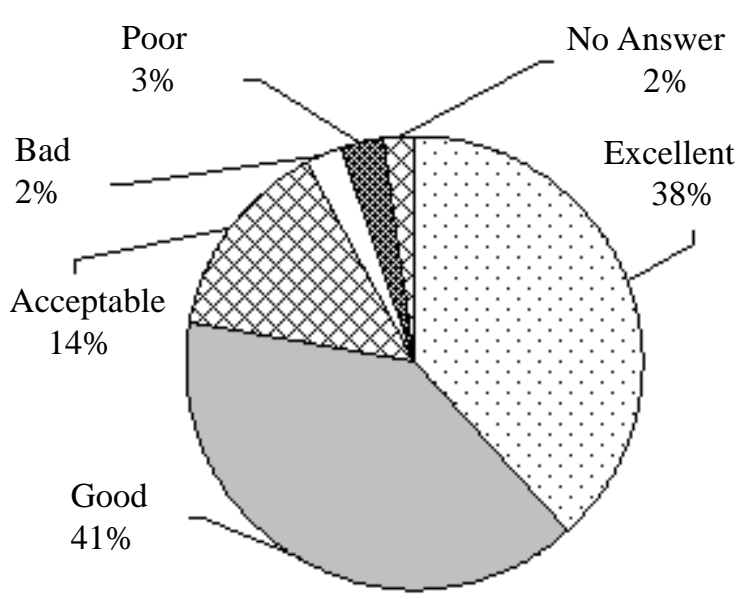

Figure 2. Pie chart for driver performance

\subsection{Driver Performance}

Figure 2 shows that only $5 \%$ of the respondents felt that driver performance was unacceptable. In fact, $79 \%$ rated the driving as either excellent or good. However, it must be pointed that this data is "softscience" in that it relates to the students' subjective interpretation about their drivers' adherence to traffic rules.

\subsection{Vehicle Condition}

Statistics on vehicle condition mirrored those of driver performance. Figure 3 shows that only a small percentage (13\%) felt that the condition of the vehicles in which they travel was unacceptable. In fact, $41 \%$ of the respondents regarded the vehicles as good while $28 \%$ felt they were in excellent condition. Once again, this was subjective data based on the passengers' interpretation of the vehicles; not reflecting the actual mechanical condition of the vehicles.

\subsection{Owner of Mode of Transportation}

Figure 4 relates to the owner of the vehicle. Spouses (46\%) were those who owned and drove the passenger

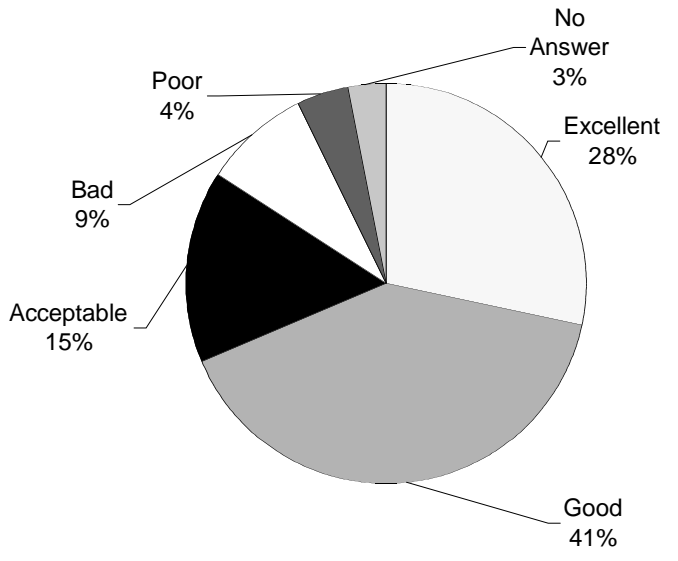

Figure 3. Pie chart for vehicle condition

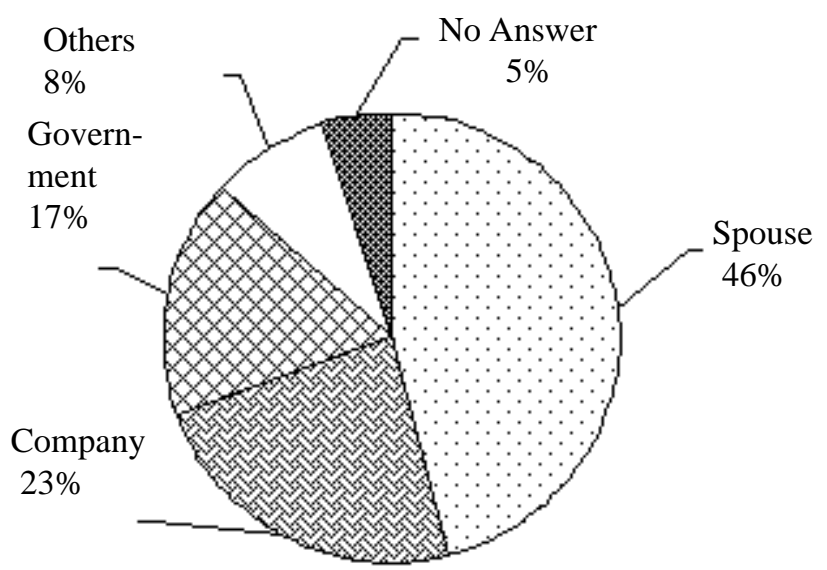

Figure 4. Pie chart for owner of mode of transportation

cars. This fact further disadvantaged students who used passenger cars for a number of reasons. First, the spouses' own study schedules must be factored into the travel plans of the students. Second, the full cost of maintaining and operating the vehicle must be borne by the spouses. Twenty three percent of the students traveling used company vehicles while $17 \%$ relied on government vehicles.

\subsection{Driver Nationality}

Figure 5 shows that about $58 \%$ of the drivers transporting female students to their colleges were Saudis. However, due to the large number of non-responses to this question (33\%), these statistics required interpretation. Therefore, it must be assumed that Saudis made up a substantial proportion of drivers. It was observed that Asians and Arabs made up 6\% and $2 \%$ of the driver population respectively.

\subsection{Mode of Transportation}

Figure 6 indicates the mode of transportation used by students. The chart shows that buses were the most common mode of transport (39\%). The second form was pas- 


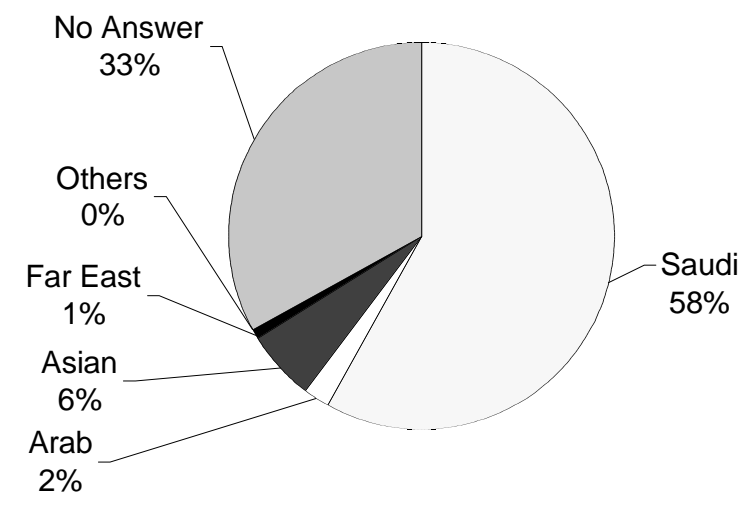

Figure 5. Pie chart for driver nationality

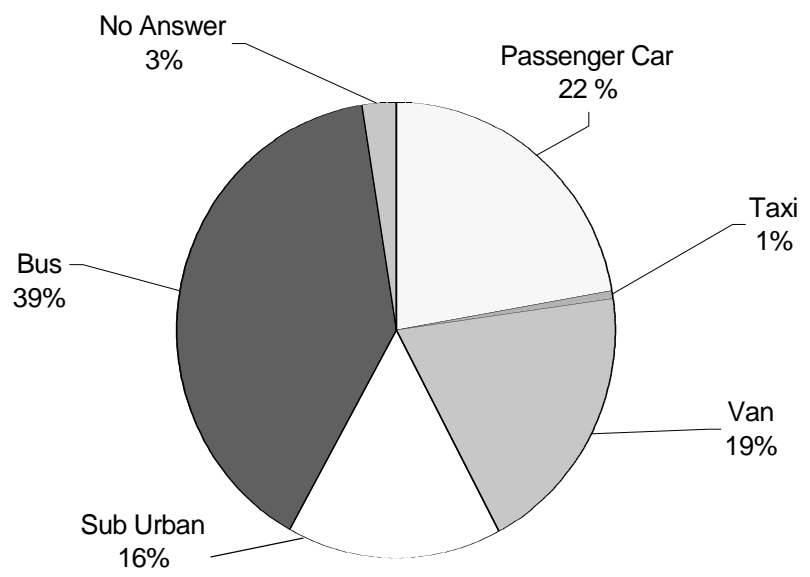

Figure 6. Pie chart for mode of transportation

senger cars (22\%), while this type of vehicle had a maximum carrying capacity of 4 passengers; the study revealed that auto occupancy ranged from 1 to 2 . The third most common vehicle category was shared by the 'suburban' (16\%) which had a capacity of 8 passengers and the minivan (19\%) which could carry up to 13 passengers. Cost was an important factor, in that passenger cars were the least cost efficient form of transport for the students due to the low vehicle occupancy.

\subsection{Reason for Choice of Mode}

There were a number of reasons for choosing a particular form of transport. From Fig. 7 it could be seen that the majority (53\%) of the respondents had to rely on their chosen form of transport because they had no other option. However, members of this group would choose another option if one were made available.

\subsection{Vehicle Manufacturer}

Figure 8 shows that Japanese and Korean vehicles made up $35 \%$ of the total. Generally, Japanese and Korean vehicles were small passenger cars with a maxi-

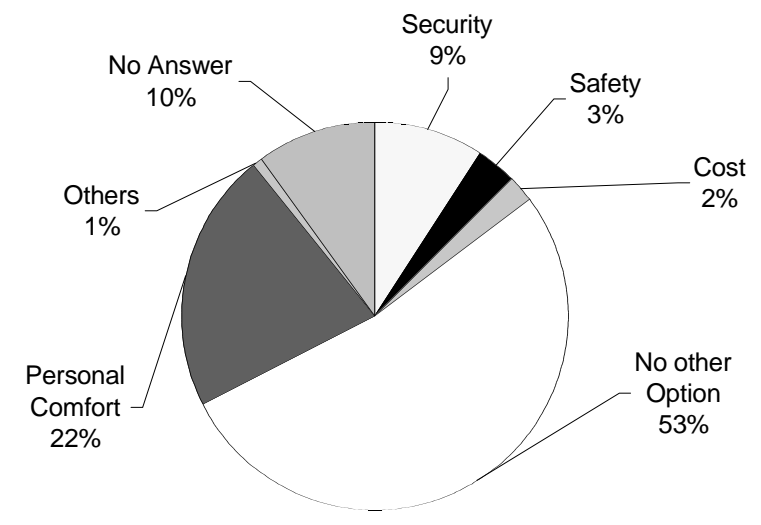

Figure 7. Pie chart for reason for choice of mode

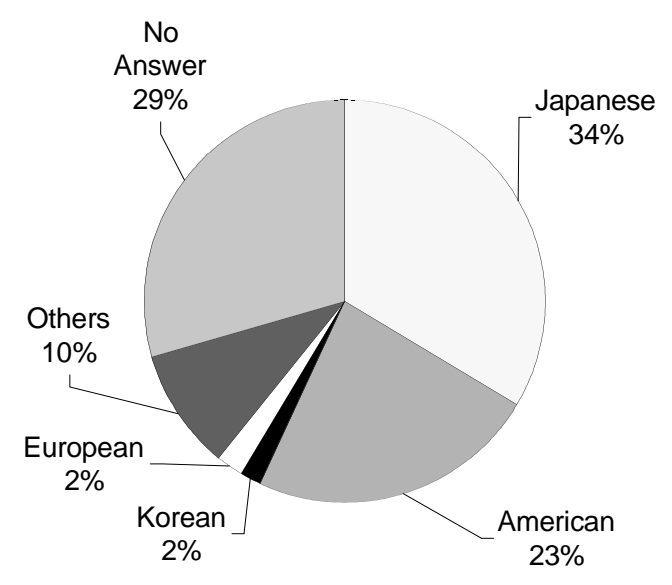

Figure 8. Pie chart for vehicle manufacturer

mum carrying capacity of 4 passengers. American vehicles (23\%), on the other hand, were larger vehicles such as the 'suburban' with a capacity of about 8 passengers.

\section{Conclusions and Recommendations}

Having carefully examined the data, several conclusions and recommendations could be suggested. These are as follows:

Female students spent, on average, 392 Riyals monthly traveling to and from college. As this is quite high, measures should be taken to reduce this cost. Special lowcost transport services could be provided or transport costs could be fully or partially subsidized by the government. In addition, travel costs could be reduced if each passenger car carried the maximum number of passengers. This could be achieved by publishing and posting special bulletins showing information of routes and costs of travel at the relevant colleges so that students could arrange a form of car pooling.

On average, students traveled for about 55 minutes and covered a distance of approximately $55 \mathrm{kms}$ one-way each 
day. This could be alleviated by providing residences for students near colleges. As it might be impractical for spouses who work in the village to live in the city, female students could stay in the accommodation during the week near the college and travel home to the village at the weekend.

While the majority of the drivers (69\%) fell into the least problematic age group, there were concerns regarding drivers at the two ends of the age spectrum. There need to be regular medical checks for drivers over the age of 50 and driver education courses for those under the age of 30 .

The majority of female students (93\%) thought that driver performance was acceptable, while 5\% thought it was unacceptable. This $5 \%$ might pose danger in causing accidents. Therefore, drivers are recommended to take special tests and permits for those driving female students to colleges.

Female students (84\%) responded that the vehicle condition was acceptable. On the other hand, 13\% believed that it was unacceptable. Therefore, it is recommended that special vehicle inspection should be done regularly for the vehicle in which female students travel.

The spouses (46\%) made substantial portion of the female student drivers.

The majority of the female students (53\%) traveling from village to city for studying did not have any other mode of choice. This made them captive to the mode they were using.

Fourteen percent of the students were married and were disproportionately disadvantaged with regards to their travel conditions. These students had associated family responsibilities. Solutions are required with respect to scheduling and travel costs. Special attention should be paid to studying schedules, and allowances should be made with respect to start/finish times to enable these students to strike an acceptable balance between their responsibilities to their families and studies.

Effort should be made for encouraging female students in villages to get higher education in universities by opening colleges in the middle distance between villages.

Acceptable government buses should be provided with experienced drivers adhering to traffic laws for transporting the female students from villages to cities.

\section{References}

Al-Ahmadi, H.M., Ratrout N., Al-Ofi K. and AlSughaiyer M., 2002, "Accident For Female Teachers and Students Traveling in Rural Areas in Saudi Arabia," Final report submitted to KACST.

Al-Shara, A. and Alsaef, K., 1988, "Analysis of the Social and Psychology Factors of the Drivers In Saudi Arabia,” Final report submitted to KACST.

Forbes, T.W., 1972, Human Factors in Highway Traffic Safety Research, New York: Wiley.

Kingdom of Saudi Arabia, Ministry of Planning, 2001, Statistical Year Book, Central Department of Statistics, Issue 36,1420 A.H.

Ministry of Education, 2001, Statistics Records, Statistics Department, Saudi Arabia 1420 A.H.

Shipp, M., 1988, "Vision Testing Policies for Driver License Renewal: Benefit or Barrier,” PhD Thesis, The University of Michigan. 